\title{
Wood Waste in Concrete Blocks Made by Vibrocompression
}

\author{
Zhi Xing $^{1} \cdot$ Chafika Djelal $^{1} \cdot$ Yannick Vanhove $^{1}$. \\ Hassina $\operatorname{Kada}^{1}$
}

Received: 28 February 2015 / Accepted: 13 August 2015 / Published online: 27 August 2015

(C) Springer International Publishing Switzerland 2015

\begin{abstract}
This paper experimentally investigates the potential use of poplar sawdust as replacement material to sand in semi-dry concrete, manufactured by vibrocompaction and used in concrete masonry blocks. The substitution of sand by wood waste can relieve the scarcity of raw materials and lighten concrete masonry block weight. The introduction of a varying proportion $(30,40,50$ and $60 \%)$ of poplar sawdust in the concrete has a significant influence on its thermophysical and mechanical behavior. The inhibition of hydration of cement with this poplar sawdust has a main influence. It affects the hydrates formed in the concrete and has an impact on the compressive strength at 7 days. This strength decreases significantly with increasing poplar sawdust proportion. But the method of concrete manufacturing by vibrocompaction increases the strength and could decrease the inhibitory effect of wood on the hydration reaction of the concrete. Substitution of $50 \%$ of sand by poplar sawdust in the masonry concrete block manufactured by vibrocompaction is proposed. Indeed, this concrete composition gives similar mechanical strength to that of the conventional manufacture of masonry concrete block.
\end{abstract}

Keywords Compaction · Concrete $\cdot$ Formulation $\cdot$ Mechanical strength $\cdot$ Poplar sawdust . Recycling

\section{Introduction}

The scarcity of raw materials and the need to develop environmentally friendly materials has led the construction sector to direct towards the use of materials from agricultural resources due to their renewability. The enormous amount of wastes produced during wood processing operations in many countries provides challenging opportunities for the use of wood waste as a

Zhi Xing

xzmaple@hotmail.com

1 Université d'Artois, LGCgE, EA 4515, 1230 Rue de l'Université, 62400 Béthune, France 
construction material (Udoeyo et al. 2006; Nguyen 2010; Cheah and Ramli 2011; Berra et al. 2015). In the most recent research, wood waste was added as a supplement in concrete mix or as a replacement of ordinary portland cement in concrete. But the substitution of sand in the concrete is also important to study because of the depletion of raw materials. The replacement of sand by wood waste gives advantages of lightness and decreases carbon dioxide emissions in the field of construction (Trouy and Triboulot 2012). For this reason, in this research, we studied sand substitution by wood waste. In the framework of ARCIR Wood research project, the Nord-Pas-de-Calais region in France was interested in recycling wood by-products in an innovative production of construction materials. The wood type studied was poplar sawdust. This is justified by the mass production of this species in the region (CRPF 2006).

In an initial study in our laboratory, we tested the feasibility of using poplar wood byproducts in a normal mortar (Xing 2013). Different proportion substitutions of sand in the mortar by poplar wood particles were tested because their granular classes are relatively close. This study showed a significant influence on the rheological and thermophysical properties. The workability of the mortar was enhanced with the increase of the substitution ratio of the sand by the wood particles until an optimum of $30 \%$. However, the problem of the hydration reaction inhibition was evidenced by a slowdown and a diminution of heat emission which led to a considerable reduction in compression strength of these mortars.

Following these results, our choice of application was oriented to semi-dry concrete blocks. This material does not require high strength and is commonly found in the construction industry. The project partner, a company in the Nord-Pas-de-Calais region in France, manufactures concrete blocks by vibrocompaction. A high frequency vibration is coupled with a compaction to produce semi-dry concrete blocks. The final product has a higher density, a better resistance and a lower permeability than that of conventional manufactured concrete (Nguyen 2010). The concept of the production is mainly based on the combination of very low water/cement (W/C) ratio and high compaction (Ling 2012). The introduction of the wood by-products in the concrete blocks by substituting some aggregates was expected to allow lightening the blocks and improving thermal and acoustic properties.

The concrete formula of our industrial partner was taken for our study as a reference. The criterion to be met by the new product developed is a compressive strength of $6 \mathrm{MPa}$ at 7 days, because the company (project partner) delivers its blocks 7 days after manufacturing. Compression tests were also carried out at 14 and 28 days. They showed the very low resistance enhancement (less than $1 \mathrm{MPa}$ ) because the product is dry; there is a high porosity in these hardened blocks. The results obtained were used for the development of concrete blocks with wood by-products by vibrocompaction.

This study proposes a method for producing a new concrete material by replacing a proportion of sand with poplar sawdust, which can be used as a building material in applications requiring low strength. Specifically, the study aims at the comprehension of the influence of the incorporation of poplar wood by-product on semi-dry concrete block properties. The role of the manufacture of concrete by vibrocompaction is also analyzed. The study includes the characterization of poplar sawdust, the effect of the proportion of sand replacement in the mix by sawdust on the thermo-physical and mechanical behavior of semidry concrete, and the determination of the optimal time and optimal vibration compaction force which result in the maximum compressive strength of the composite concrete. The tests of the research were performed according to the relevant international standards. 


\section{Characterization of Poplar Sawdust}

Poplar sawdust used (Fig. 1a) is Robusta provided by the company project partner in the NordPas-de-Calais region in France. This sawdust is a by-product of sawing. Microscope observation showed an irregular and rough shape with vegetable fibers having a preferential direction (Fig. 1b). This specific morphology may influence the adhesion between the poplar particles and the binder. Particle size analysis was performed according to the XP P 18-545 standard (Fig. 1c). $94 \%$ of the sawdust has a size less than $2 \mathrm{~mm}$.

The method for determining the density and water absorption coefficient of lightweight aggregates in the NF EN 1097-6 standard is used to characterize the poplar sawdust (Table 1). These measurements were performed on bulk samples without compaction. The absorption coefficient was found $174 \%$, which is due to the high porosity of the sawdust. This characteristic should be taken into account in the concrete formulation and concrete mixing (Fig. 2). Absorption kinetics showed a saturation time of $2 \mathrm{~min}$. One must, therefore, respect the wetting time for the poplar sawdust (Xing 2013).

\section{Wood Concrete Composition}

The study is based on different substitutions of sand by poplar sawdust in the reference concrete formula because the sand granular class is close to that of sawdust. The optimum substitution of $30 \%$ is found in the preliminary study on the mortars, and for this reason, our
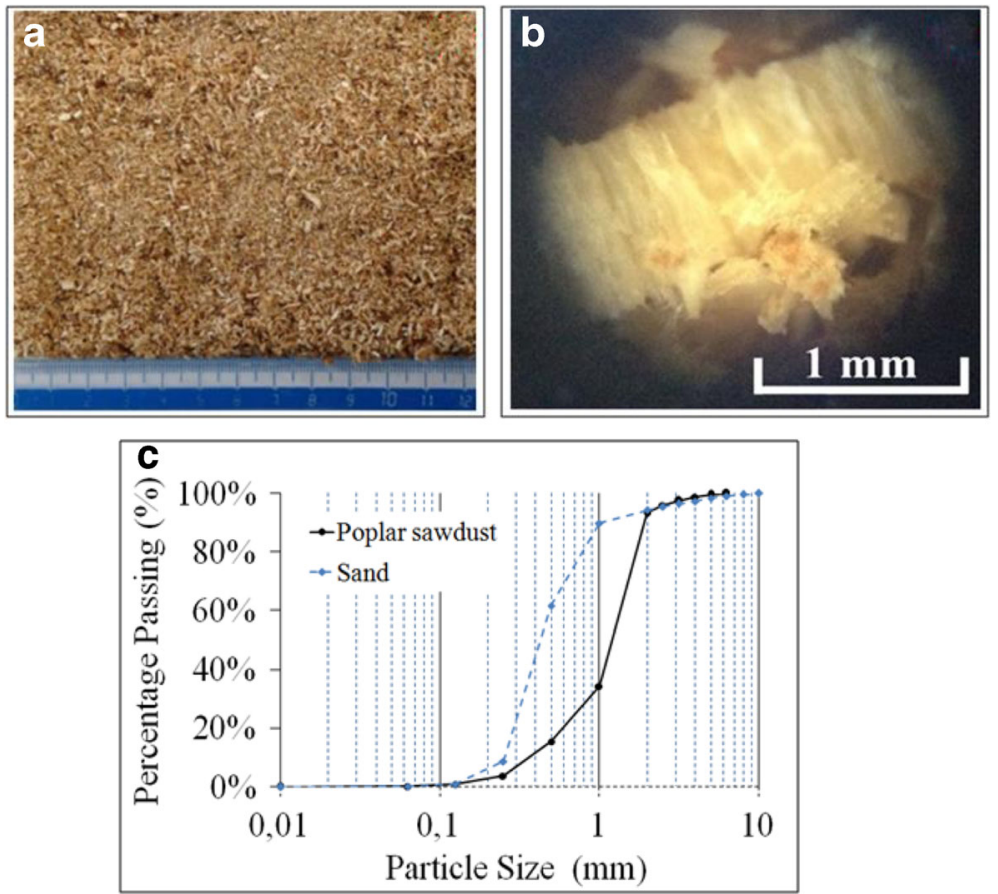

Fig. 1 Poplar sawdust used: a naked eye; b under microscope (magnification 10 times); c particle size distributions 
Table 1 Density and water absorption coefficient of poplar sawdust
Poplar sawdust

\begin{tabular}{ll}
\hline Apparent density $\left(\mathrm{kg} \cdot \mathrm{m}^{-3}\right)$ & 178 \\
Saturated and surface-dried density $\left(\mathrm{kg} \cdot \mathrm{m}^{-3}\right)$ & 390 \\
Water absorption $(\%)$ & 174 \\
\hline
\end{tabular}

first substitution ratio for poplar sawdust concrete (PSC) was $30 \%$ (Xing 2013). Three other volume substitution ratios $(40 \%, 50 \%$ and $60 \%)$ were also studied to optimize the concrete formulation (Table 2).

The compositions are given in Table 2. The cement used was of type CEM I 52.5. Its chemical composition is presented in Table 3 . The sand was siliceous marine sand with a water absorption coefficient of $0.49 \%$. Two granular classes of crushed calcareous aggregate $2 /$ $4 \mathrm{~mm}$ and 4/6 mm were also used. The mixing protocol for PSC concrete is shown in Fig. 2. In fresh state, the concrete was dry, very firm and slightly cohesive because of a low volume of pastry $(16 \%)$ in their formulation.

\section{Wood Concrete PSC Maturity}

The hydration of PSC concrete was studied using an isothermal calorimeter at a temperature of $20{ }^{\circ} \mathrm{C}$ (Fig. 3). The sample studied is a square prism of dimensions $15 \times 15 \mathrm{~cm}^{2}$ and $6 \mathrm{~cm}$ thick. The frequency of acquisition is $5 \mathrm{~min}$. The main interest of the isothermal calorimetry is bound to maintain the reaction temperature, which is a fundamental advance for the study of thermoactive chemical processes through the measurements of heat flow for the maturity analysis. The calorimetry device consists essentially of four parts which are a sample holder, a thermal control system, instrumentation sensors and an acquisition chain. The two plates are connected to a thermostatic bath by two pumps which provide a sufficient flow to ensure the circulation of the heat transfer fluid of the thermostatic bath, to maintain constant temperature and keep isothermal reaction condition. Flow sensors are plated on the surface of the exchange plates. T-type thermocouples (copper/constantan) were placed on the sides and the heart of the sample to measure temperatures.

Table 2 Composition of poplar sawdust concrete (data for $1 \mathrm{~m}^{3}$ )

\begin{tabular}{llllll}
\hline$\left[\mathrm{kg} / \mathrm{m}^{3}\right]$ & PSC0 & PSC30 & PSC40 & PSC50 & PSC60 \\
\hline Cement CEM I 52.5 & 177 & 177 & 177 & 177 & 177 \\
0/4 sand & 591 & 413 & 354 & 295 & 236 \\
2/4 calcareous & 517 & 517 & 517 & 517 & 517 \\
4/6 calcareous & 1107 & 1107 & 1107 & 1107 & 1107 \\
Effective water & 105 & 105 & 105 & 105 & 105 \\
Poplar sawdust & 0 & 26 & 35 & 44 & 53 \\
[\%/ sand volume $]$ & $0 \%$ & $30 \%$ & $40 \%$ & $50 \%$ & $60 \%$ \\
Density & 2497 & 2345 & 2295 & 2245 & 2195 \\
W/C & 0.59 & 0.59 & 0.59 & 0.59 & 0.59 \\
\hline
\end{tabular}


Table 3 Chemical composition of cement CEM I 52.5

\begin{tabular}{lllllllllllll}
\hline Oxides & $\mathrm{SiO}_{2}$ & $\mathrm{Al}_{2} \mathrm{O}_{3}$ & $\mathrm{Fe}_{2} \mathrm{O}_{3}$ & $\mathrm{CaO}$ & $\mathrm{MgO}$ & $\mathrm{SO}_{3}$ & $\mathrm{~K}_{2} \mathrm{O}$ & $\mathrm{Na}_{2} \mathrm{O}$ & $\mathrm{C}_{3} \mathrm{~S}$ & $\mathrm{C}_{2} \mathrm{~S}$ & $\mathrm{C}_{3} \mathrm{~A}$ & $\mathrm{C}_{4} \mathrm{AF}$ \\
\hline$(\%)$ & 20.4 & 5.0 & 3.2 & 63.8 & 0.9 & 3.1 & 0.79 & 0.24 & 58 & 15 & 8 & 11 \\
\hline
\end{tabular}

The heat flow evolution of PSC concrete with different substitutions ratio as function of time is shown in Fig. 4a. A decrease of the maximum heat flux of different PSC concrete mixes and a slowdown of hydration reaction kinetics were observed. The hydrates formed were affected by the presence of poplar sawdust particles in the composite. A delay and a progressive decrease of the reaction peak were observed between PSC0 and PSC60, which means that the mechanical strengths of PSC concretes gradually decrease. The quantity of PSC concrete heat emission was obtained by the integration of the flow (Fig. 4b). We note that the hydration heat of PSC concrete decreases with the increase of the amount of sawdust substituted for a 3-day recording time, which shows the decrease of the quantity of formed hydrates that are affected by the amount of sawdust used. These observations can explain the difference between the mechanical strengths of PSC. The degree of hydration of PSC can be calculated by the ratio of the measured heat and the heat of ultimate hydration. The ultimate hydration heat was calculated according to the heat release of four main mineralogical components as $\mathrm{C}_{3} \mathrm{~S}, \mathrm{C}_{2} \mathrm{~S}, \mathrm{C}_{3} \mathrm{~A}$ et $\mathrm{C}_{4} \mathrm{AF}$ using the composition of Bogue (Neville 2000). The heat release of the calculated ultimate hydration was $474.06 \mathrm{~J} / \mathrm{g}$ for the cement. The influence of adding sawdust particles on the PSC hydration degree is observed in Fig. 4b. For a 3-day recording time, the PSC hydration degree is slown to follow the sand substitution ratio by poplar sawdust.

Observations from isothermal calorimetric measurements on PSC show the role of the incorporation of poplar sawdust in concrete. This use of sawdust may decrease the flow and the amount of heat release and slow the hydration degree of cementitious material. This property obviously influences poplar sawdust concrete made by vibrocompaction.

\section{Wood Concrete PSC Development by Vibrocompaction}

A compactor with one cylinder for vibrocompaction (pneumatic vibrator) was used for the manufacture of PSC samples (Fig. 5). The cylinder has a size of $100 \mathrm{~mm}$ in diameter and $200 \mathrm{~mm}$ in height. The wood concrete is introduced into the cylinders with 2 identical layers of $1.7 \mathrm{~kg}$ each.

The vibration duration of each layer of PSC was $15 \mathrm{~s}$ (determined on a series of calibration tests). The desired compaction force is then applied to the sample. The vibrocompaction is performed using a vibration in the horizontal plane and a vertical increasing axial force applied, by means of a piston, to the entire section of the specimen. A maximum pressure of

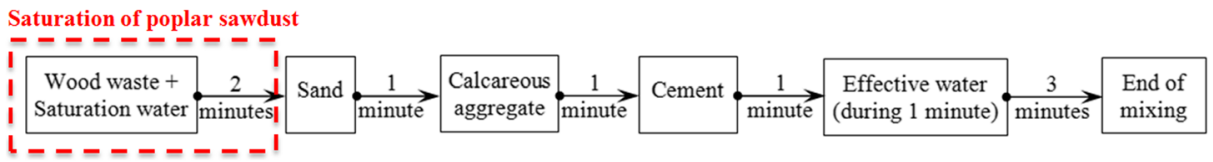

Fig. 2 Protocol for poplar sawdust concrete preparation 


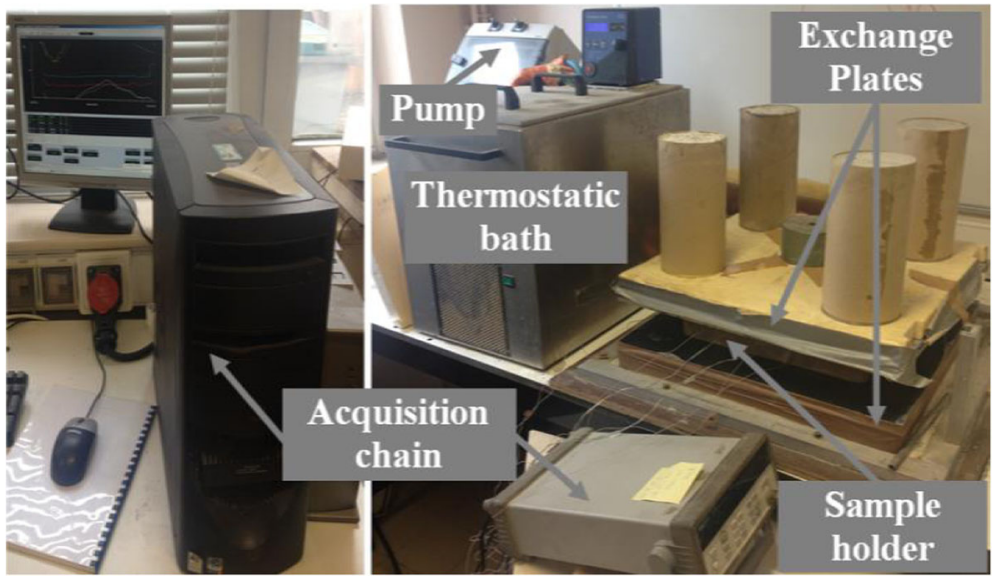

Fig. 3 Device of isothermal calorimetry

6 bars can be generated by the pneumatic jack operating with compressed air. The desired compaction pressure is reached after 2 or $3 \mathrm{~s}$. The vibration has a frequency of $250 \mathrm{~Hz}$ and amplitude of $2 \mathrm{~mm}$. The combined action of compaction and vibration prompts a granular arrangement of concrete which leads very quickly to a good compactness.

\subsection{Choice of Vibration Time and Compaction Force}

The vibration time and the compaction force used are the main parameters that will influence the development of concrete made by vibrocompaction and its mechanical properties. The optimum vibration time was determined by a series of compactness test for 3 concrete mixes (PSC0, PSC30 and PSC60). The compactness was calculated by taking the ratio of the concrete vibrated volume to the initial volume for one layer of wood concrete $(1.7 \mathrm{~kg})$ at different times of vibration. The results are given in Fig. 6.

We can observe, in Fig. 6, a vibration of $15 \mathrm{~s}$ gives optimum compactness for 3 wood concrete mixes. This optimum vibration time is common for the PSC concrete mixes.

The value of the compaction stress for the manufacture of the wood concrete was determined from the measurements of mechanical strength at 7 days on three specimens $\varnothing 10 \times 20 \mathrm{~cm}$ according to EN 12390-3 because of the product delivery time of the production
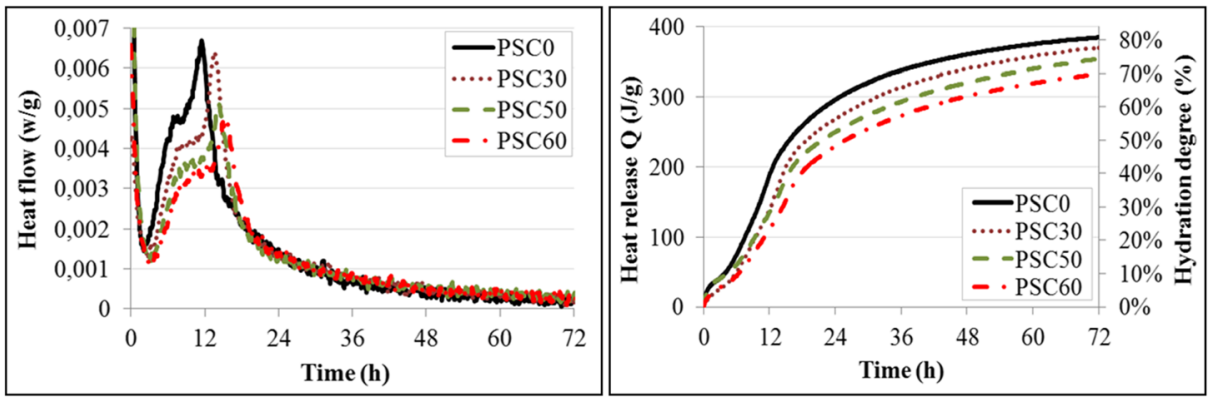

Fig. 4 Evolution of PSC calorimetric measurements: heat flow versus time (left); heat release and hydration degree (right) 

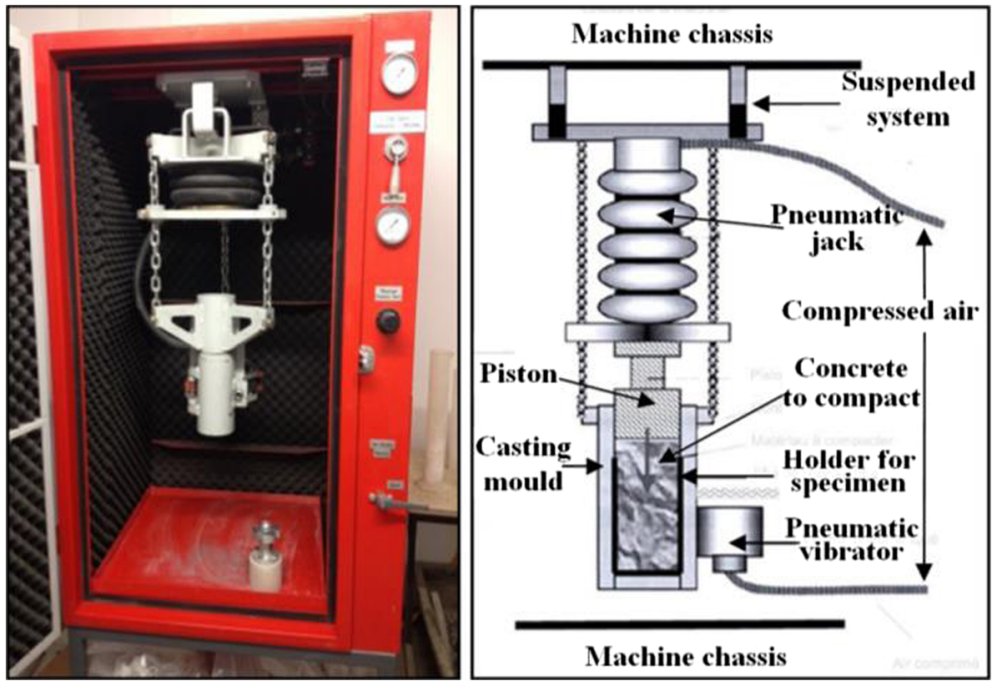

Fig. 5 Diagram of the inner part of the vibrocompaction chamber

factory. The compression tests were also carried out at 28 days and showed a very low resistance evolution (less than $1 \mathrm{MPa}$ for the sample manufactured without compaction force and less than $2 \mathrm{MPa}$ for the sample made with compaction force) because the porosity of the specimen was high. The specimens were removed from the mold and placed in sealed plastic bags $24 \mathrm{~h}$ after casting until the desired test, according to EN 12390-2. The results are given in Fig. 7.

The manufacture of the specimens by vibrocompaction increases the mechanical strength of the mixture. The mechanical strength of concrete mixes PSC0, PSC30 and PSC60 increased to the optimum for a compaction stress of $40 \mathrm{kPa}(1.8 \mathrm{kN})$. Beyond this stress, the mechanical strength decreased. As the device quickly reaches the desired compaction stress, this decrease can be explained for PSC0, PSC30 and PSC60 by the speed of the introduction of the high load that blocks the granular arrangement of concrete under vibration.

The decrease in the mass of the blocks is an important parameter for the development of wood concrete PSC. The mass of the specimens were measured in the fresh state. The evolution of the mass density as a function of compaction stress is given in Fig. 8. Compaction increases the density of the test specimens. For each compaction stress, the

Fig. 6 Evolution of PSC compactness as a function of vibration time

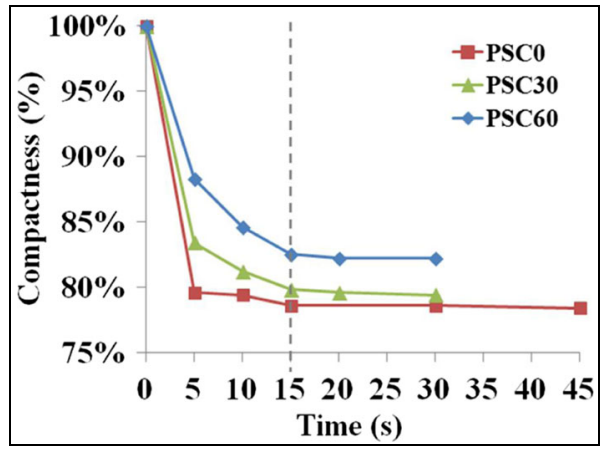



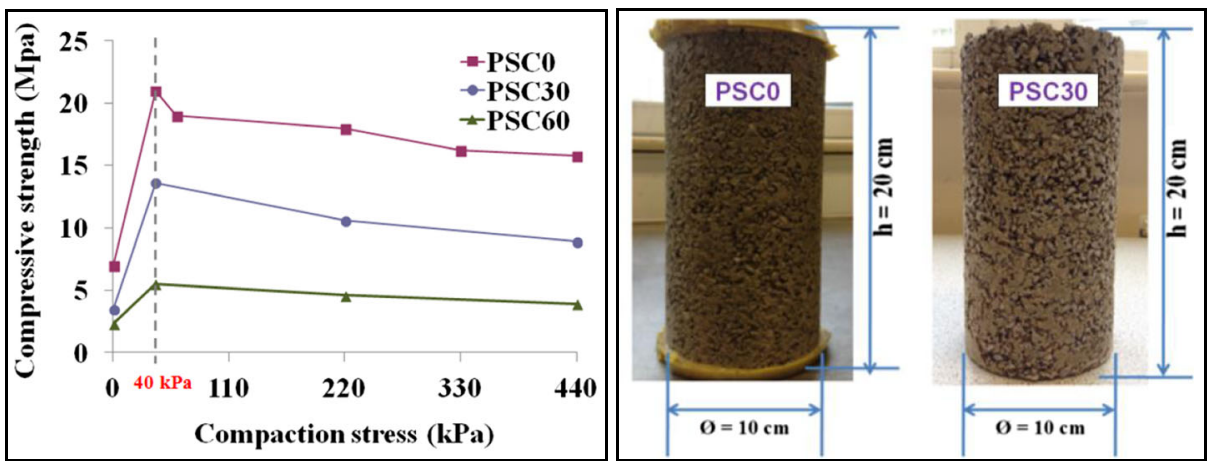

Fig. 7 Evolution of compressive strength as a function of compaction stress $(l e f t)$ and the specimens PSC0 and PSC30 at 7 days (right)

substitution of sand by the poplar sawdust makes a lighter concrete. We can observe a decrease in mass when the stress increases after $40 \mathrm{kPa}$, which is consistent with the decrease in the compressive strength of the PSC concrete at 7 days following the compaction stress.

The formulation of PSC0 concrete corresponds to concrete blocks manufactured by the company of project partner. These specimens are our reference test. The mechanical strength reaches $7 \mathrm{MPa}$ at 7 days without the application of a compaction stress. It can triple when using the vibrocompaction process with a compaction stress of $40 \mathrm{kPa}$. This result is almost the same as that of Ling (2012). An increase of 2.5 times of the compressive strength for the concrete block manufactured by vibrocompaction was observed in his research in comparison to conventional production. The incorporation of poplar sawdust in the cementitious composite greatly reduces its mechanical performance (50\% diminution for $30 \%$ sand substitution by sawdust; Fig. 7). The application of a compaction force allows for the increase of the mechanical strength of the concrete specimens.

\subsection{Optimization of PSC Formulation}

To optimize the formulation of poplar wood concrete, the substitution ratios of 30, 40, 50 and $60 \%$ were studied. The evolution of the compressive strength at 7 days is given as a function of compaction (Fig. 9).

Fig. 8 Evolution of the fresh concrete mass density of PSC0, PSC30 and PSC60 as a function of different compaction stress

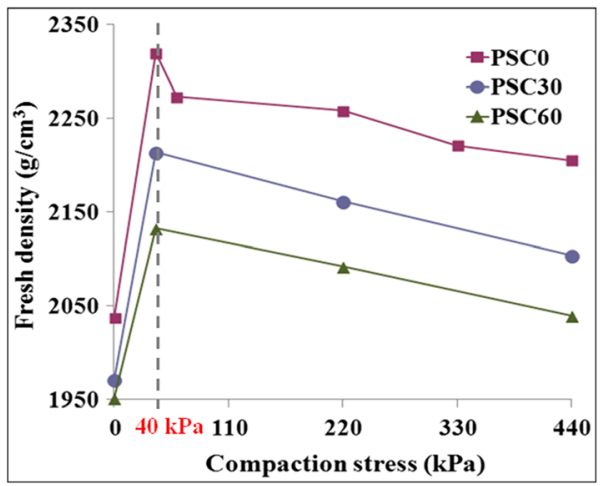


Fig. 9 Evolution of compressive strength of PSC at 7 days as a function of different compaction stress

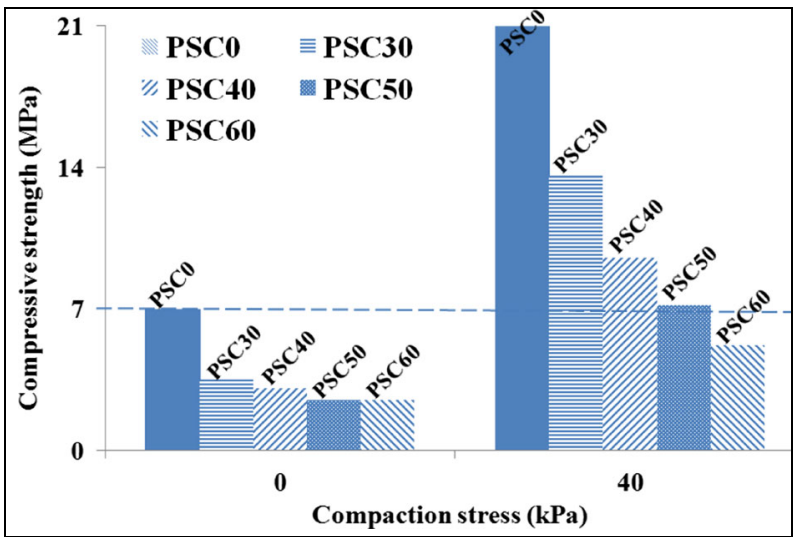

The incorporation of poplar sawdust in PSC concrete greatly influences its mechanical performance. Compressive strength decreases according to the substitution degree in the concrete due to the inhibition of the wood on the hydration reaction of cementitious composite obtained from the isothermal calorimetry (Fig. 4). The decrease in the strength reaches $50 \%$ for PSC30, $56 \%$ for PSC40 and $64 \%$ for PSC50 without compaction stress during the manufacture of the specimens. The strength of PSC60 is almost $1 / 3$ that of PSC 0 at 7 days. For all the PSC, the manufacture of the concrete mixes by vibrocompaction increases their compressive strengths.

The comparison of the mechanical strengths of PSC with and without poplar sawdust show that the presence of the compaction stress significantly increases the compressive strength of PSC at 7 days. We can observe that the rate of increase of compressive strengths can be slowed according to the sawdust substitution ratio. The vibrocompaction decreases the inhibitory effect of the wood on hydration reaction of the cementitious composite and leads to an improvement of the mechanical performance limits. A proposed substitute of $50 \%$ sand by poplar sawdust in PSC may be proposed in the face of its mechanical properties for the realization of a wood concrete at an industrial scale by vibrocompaction.

\section{Conclusions}

The study of the incorporation of poplar sawdust in concrete made by vibrocompaction showed that it is possible to develop wood concrete blocks with a mechanical strength greater than $6 \mathrm{Mpa}$ and to decrease weight. The inhibition of the setting of concrete with poplar sawdust is characterized by maturity tests that affect its mechanical strength. This strength decreases significantly with increasing poplar sawdust proportion. The decrease of the strength reaches $50 \%$ for a concrete with a $30 \%$ sand substitution by sawdust, and $65 \%$ with a $60 \%$ substitution. The method of concrete manufacture by vibrocompaction increases its mechanical strength. A compaction stress and a vibration time duration were optimized in this study at $40 \mathrm{kPa}$ and and $15 \mathrm{~s}$, respectively. In the case of concrete with $0 \%$ poplar sawdust, the vibrocompaction performed at a $40 \mathrm{kPa}$ stress results in a strength increase by 3 times in comparison to non-compacted concrete, and beyond this force, the concrete strength decreases. An almost $100 \%$ increase of mechanical strength is observed for the concrete with $30 \%$ 
poplar sawdust substitution and $40 \%$ increase for $40 \%$ substitution, which could, in the case of our concrete, decrease the effect of wood inhibition on the hydration reaction. A proposal for $50 \%$ sand substitution by poplar sawdust in the PSC concrete is retained. Indeed, this concrete composition gives similar mechanical strength to that of the reference concrete for the manufacture of masonry concrete blocks.

Acknowledgments An initial version of this paper has been presented at the International Conference on Integrated Management of Environment (http://www.icime.net), 25-28 September 2014, Hammamet, Tunisia.

\section{References}

Berra M, Mangialardi T, Paolini A (2015) Reuse of woody biomass fly ash in cement-based materials. Constr Build Mater 76:286-296

Cheah C, Ramli M (2011) The implementation of wood waste ash as a partial cement replacement material in the production of structural grade concrete and mortar: an overview. Resour Conserv Recycl 55:669-685

CRPF (2006) Schéma Régional de Gestion Sylvicole, Tome 1, Centre Régional de la Propriété Forestière, NordPas-de-Calais Picardie, Amiens, France

Ling TC (2012) Effects of compaction method and rubber content on the properties of concrete paving blocks. Constr Build Mater 28:164-175

Neville AM (2000) Propriétés des Bétons. Editions Eyrolles, Paris

Nguyen TT (2010) Contribution à l'étude de la formulation et du procédé de fabrication d'éléments de construction en béton de chanvre. Thèse, Université Bretagne-Sud, France

Trouy MC, Triboulot P (2012) Matériau bois - structure et caractéristiques. Tech de l'Ingénieur C925:1-26

Udoeyo F, Inyang H, Young D, Oparadu E (2006) Potential of wood waste ash as an additive in concrete. J Mater Civ Eng 18:605-611

Xing Z (2013) Effet du peuplier sur le mortier, Avancement de projet ARCIR CLUSTER Bois, Equipe Matériaux Béton Composite, Axe Géomatériaux. IUT Béthune - Université d'Artois, France 